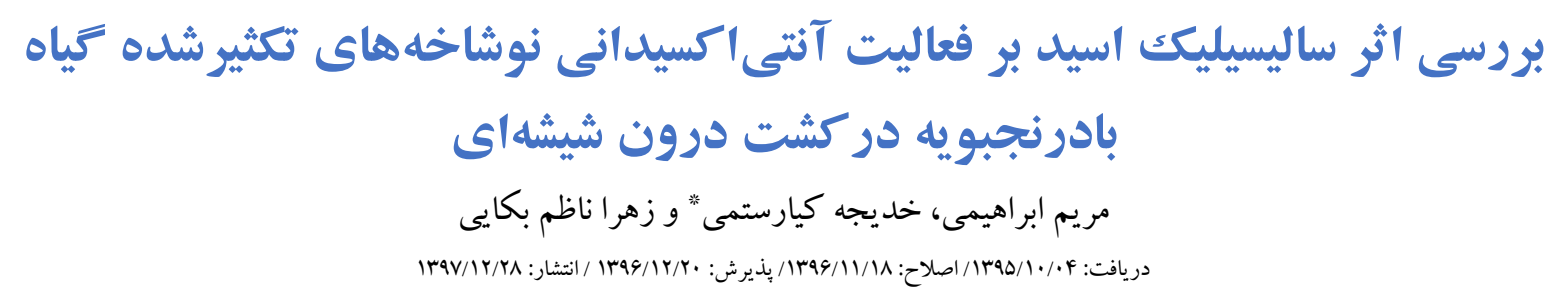

$$
\text { كروه علوم گياهى، دانشكدة علوم زيستى، دانشكاه الزهرا، تهران، ايران }
$$

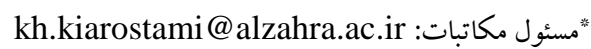

$$
\begin{aligned}
& \text { جكيده. بادرنجبويه گياهى است دارويى از تيرهٔ نعنائيان كه بهعلت خو اص درمانى خود در بسيارى از نقاط دنيا كشت مىشود. اين يزوهش به منظور بهينه سازى فعاليت }
\end{aligned}
$$

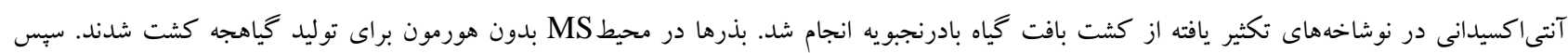

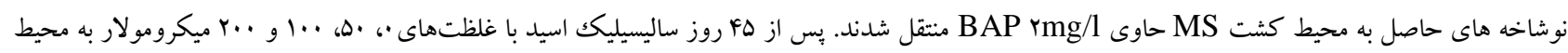

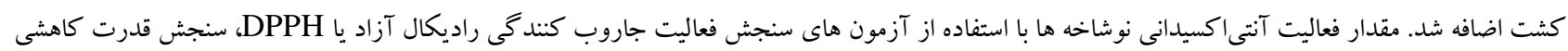

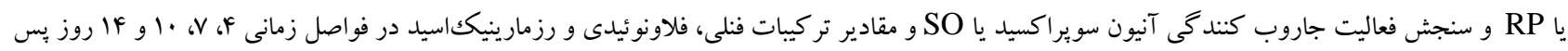

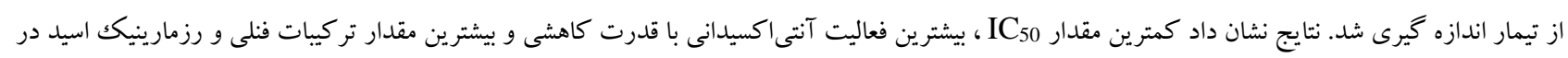

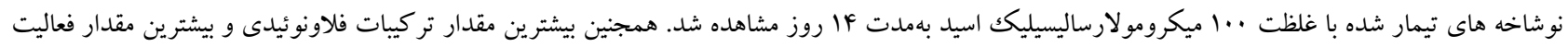

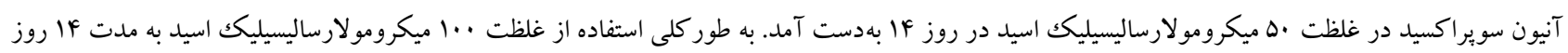

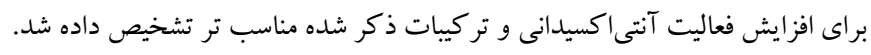

$$
\begin{aligned}
& \text { وازههاى كليدى. تر كيبات فنلى، تنظيم كننده رشد كياهى، رزمارينيك اسيد، فلاونوئيدها، نعنائيان }
\end{aligned}
$$

\title{
Effect of salicylic acid on antioxidant properties of in vitro proliferated shoots of Melissa officinalis $\mathbf{L}$.
}

\author{
Maryam Ebrahimi, Khadijeh Kiarostami * \& Zahra Nazem Bokaee \\ Received 25.12.2016/ Revised 07.02.2018/ Accepted 11.03.2018/ Published 19.03.2019
}

Department of Plant Biology, Faculty of Biological Science, Alzahra University, Tehran, Iran

*Correspondent author: kh.kiarostami@alzahra.ac.ir Abstract. Melissa officinalis is a medicinal plant belonging to Lamiacea family. This plant has been cultivated in many
parts of the world due to its therapeutic effects. This study was conducted to improve the antioxidant activities of
Melissa officinalis proliferated shoots obtained from tissue culture. The seeds were cultured in MS hormone-free
medium in order to obtain seedlings. The shoots were then transferred to MS medium supplemented with 2 mg/ L BAP.
Salicylic acid (SA) was added to the medium at concentrations of $0,50,100$ and $200 \mu \mathrm{M}$ after 45 days. The antioxidant
activity by the methods of free radical scavenging (DPPH), reducing power (RP) and superoxide anion scavenging
activity (SO) was measured and the phenolics, flavonoids and rosmarinic acid contents were evaluated in proliferated
shoots, $4,7,10$ and 14 days after treatment. As a result, the highest free radical scavenging and RP activity, as well as the
highest value of total phenolic and rosmarinic acid, were observed in shoots after 14 days of treatment with $100 \mu \mathrm{M}$
SA. The elevated level of SO activity and total flavonoids were obtained from the shoots treated with $50 \mu \mathrm{M}$ SA for 14
days. In general, treatment with $100 \mu \mathrm{M}$ SA for 14 days was proved to be better for the increase of antioxidant activity
and the amount of the compounds with recognized antioxidant activity.

Keywords. flavonoids, Lamiaceae, phenolic compounds, plant growth regulator, rosmarinic acid 
تأثير ساليسيليكاسيد القا مىشود. آنزيمهاى مسير فنيل برويانوئيد

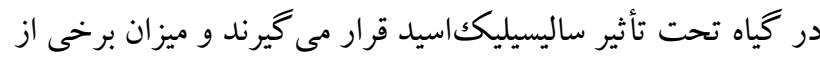
متابوليتهاى ثانوى مانند تركيبات فنلى را افزايش مىدهير

.(Buitelaar et al., 1992)

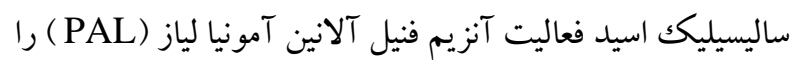
تنظيم مى كند. اين آنزيم واكنشهاى بيوسنتزى تشكيل تركيبات

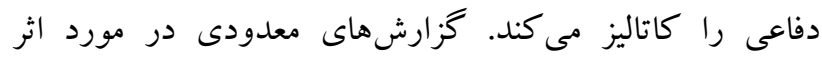

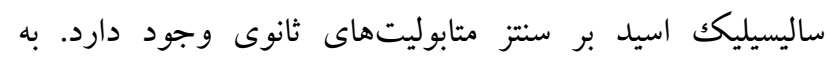
كزارش شبرنگى و بيكى جازى (2014) محتواى تر كيبات فنلى در

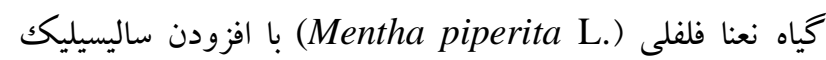

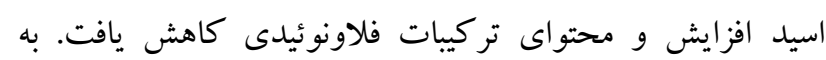

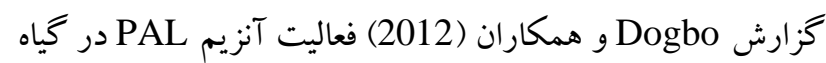
كاساوا (Manihot esculenta) تحت تأثير ساليسيليك اسيد به

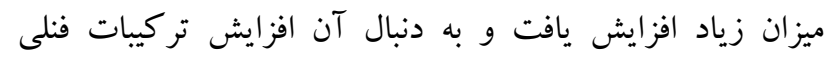

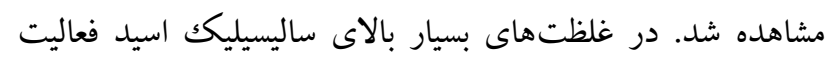

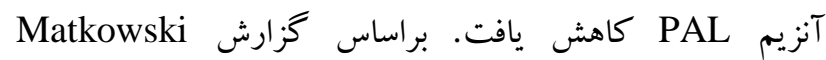
(2008) ساليسيليك اسيد در كشت ريشه موئين گياه ريحان بران

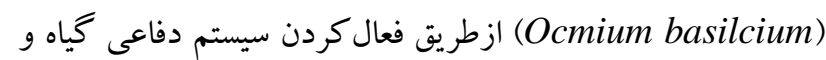
به دنبال آن القاى مسير فنيل يرويانوئيد باعث افزايش توليد

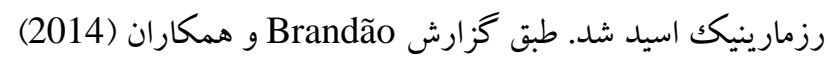
ساليسيليك اسيد در آناغاليس (Anagallis tenella) سنتز بتاسيانين را افزايش مىدهد ولى باعث افزايش در غلظت

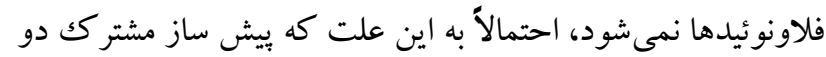

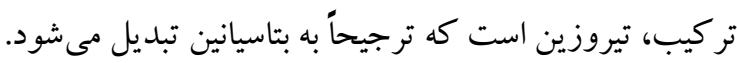

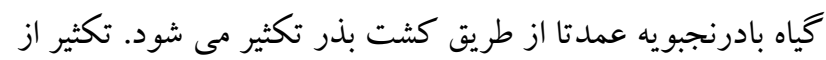

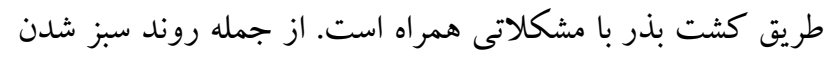

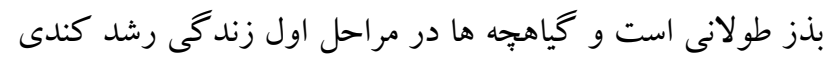

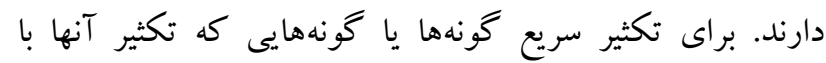

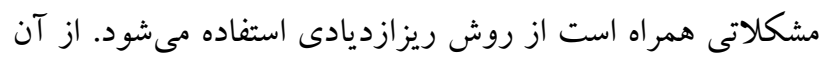
جايى كه تكثير گياه بادرنجبويه در طبيعت به كندى انجام مى شوده،

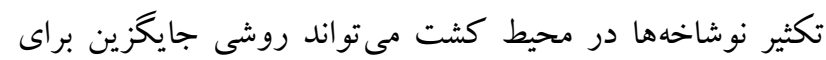

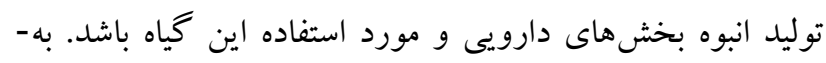

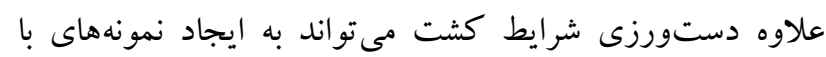

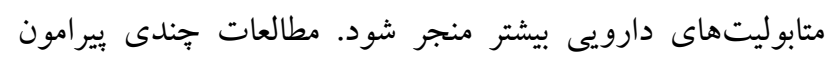

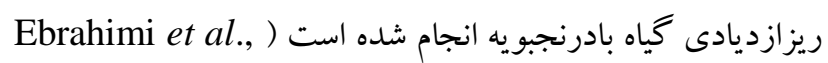

مقام

بادرنجبويه (Melissa officinalis. L.) خياهى دارويى، علفى و وبايا از تيرة نعنائيان است. از رايجترين خواص درمانى بادرنجبويه

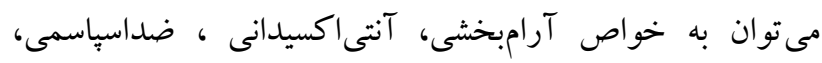

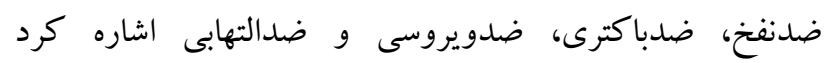
(Yosofi et al., 2011)

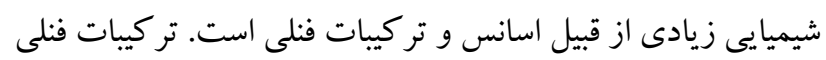

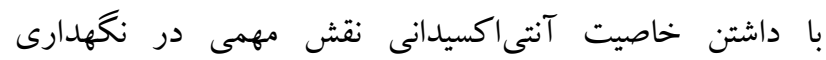
محصو لات غذايى و حفظ سلامتى انسان ايفا مى كنند و به عنوان

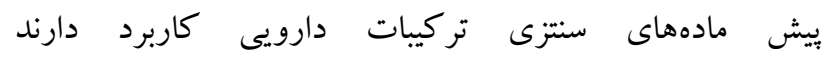
(Mohamadi et al., 2014; Raghavendra et al., 2010) بادرنجبويه حاوى مقادير زيادى رزمارينيك اسيد است بهنحوى كه رزمارينيك اسيد در همه اندامهاى گياه بادرنجبويه يافت مى مئدود (Weitzel \& Petersen, 2011)

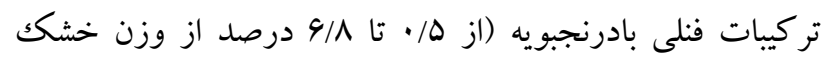
كياه) را به خود اختصاص مىدهد (Peeva et al., 2011). Ozturk et al., ) رزمارينيكاسيد در كنار فعاليت آنتى اكسيدانى

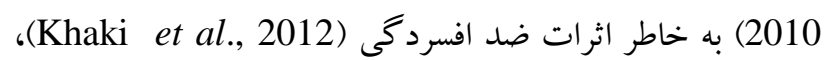
ضد آرتروز (Fletcher et al., 2005) و ضد سرطان (Shahadat Hossan et al., 2014) بادرنجبويه در كنار رزمارينيك اسيد حاوى فلاونوئيدهايى مانند سيناروزيد، كاسموزين، ايزوكوئرستين و رامنوسيترين (Ondrejovic et al., 2012) كاربرد برونزاى برخى از تركيبات ازجمله تنظيم كنندهاى رشد

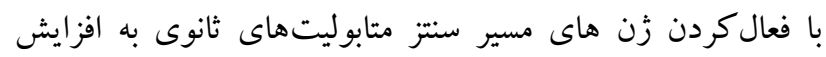
تجمع اين متابوليتها منجر مىشود. ساليسيليك اسيد يكك تنظيم-

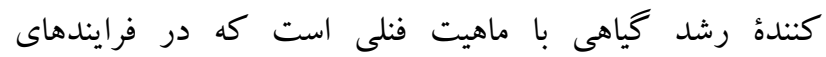

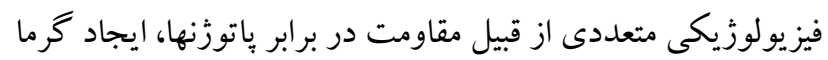

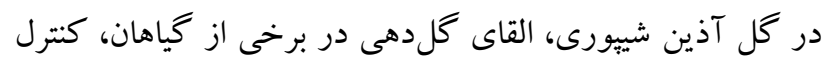

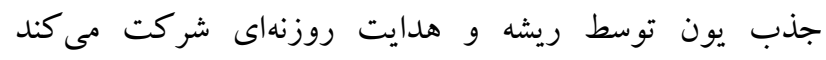
(Raskin, 1992; Hayat et al., 2008) ساليسيليك اسيد، تحمل گياه در برابر فلزات سمى ، گرما، سرما و تنش شورى را بهبود مى دهد, Sakhanokho \& Kelley, 2009; Rowshan et al., 2010; Kiarostami et al., (2013. بيان برخى از زنهاى توليد كنندة متابوليتهاى ثانوى تحت 
رزمارينيك اسيد با استفاده از منحنى استاندارد رزمارينيك اسيد با

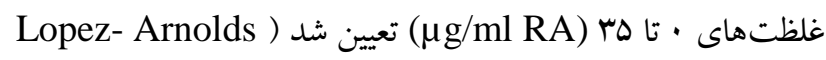
.et al., 1995

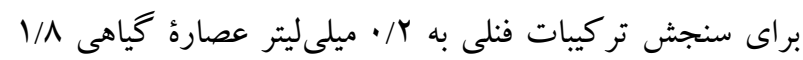

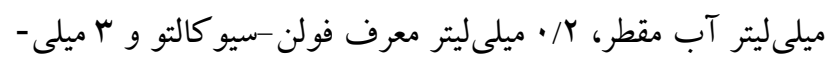

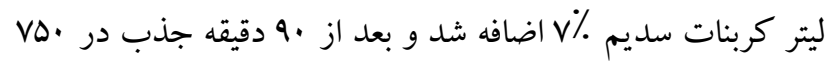

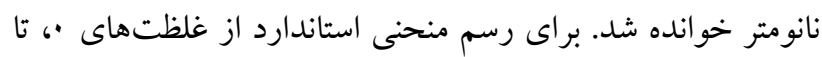

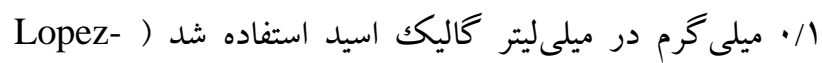
.(Arnolds et al., 2001 مقدار تركيبات فلاونوئيدى عصارهها با استفاده از روش رنغك

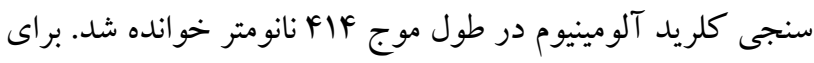

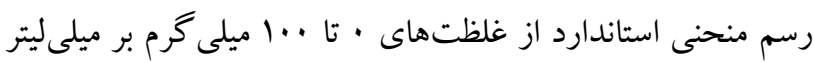
كوئرستين استفاده شد (Kulisic et al., 2008).

\section{سنجش فعاليت آنتىاكسيدانى عصارهها سنجش فعاليت

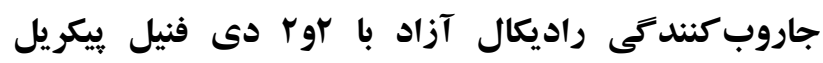
هيدرازيل (DPPH)

براى سنجش فعاليت جاروب كنندگى راديكال آزاد با DPPH

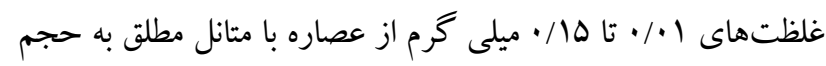

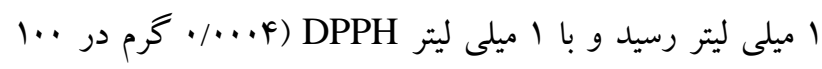

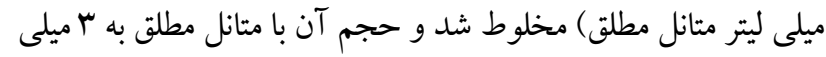
ليتر رسيد. پِ از ها دقيقه جذب در مقابل بلانكك (1 ميلى ليتر

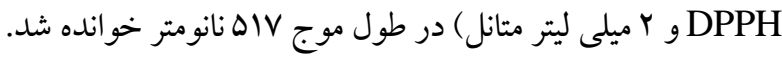
درصد مهار راديكال آزاد توسط عصاره گياهى با استفاده از

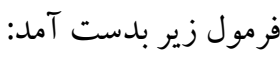

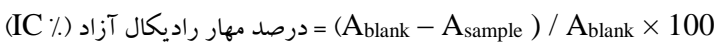

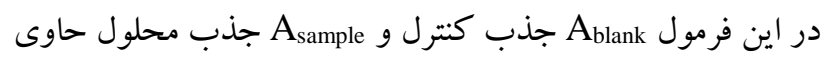
نمونه گياهى است (Molyneux, 2004).

سنجش قدرت كاهشى يا Reducing Power (RP)

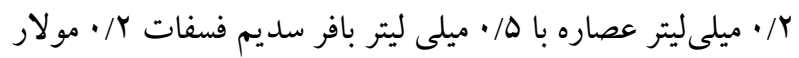

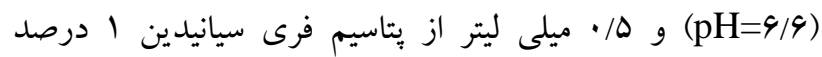

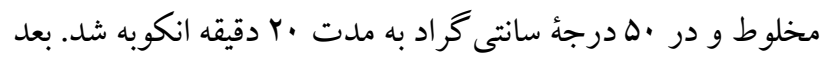

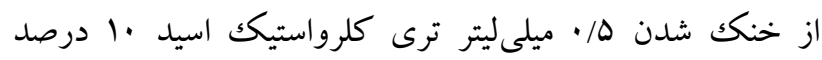

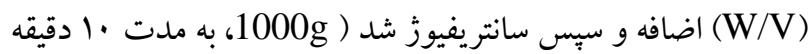

$$
\text { ، دمر دماى f مرجه سانتى گر اد). }
$$

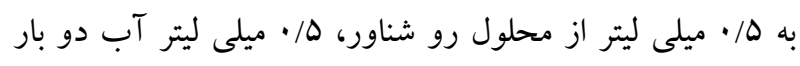

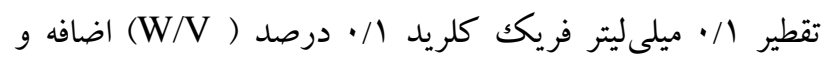

2015 ; Meftahizade et al., 2010; Meftahizade et al., ف 2012; Mohebalipour et al., 2012 فعال زيستى گياهان تكثير شده مورد بررسى قرار نخرفته است. اين

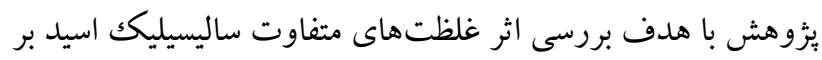

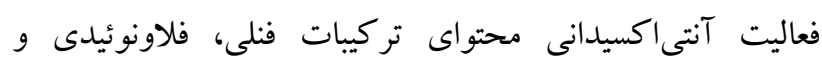

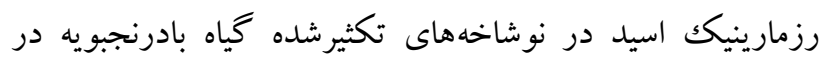
كشت درون شيشهاى گياه انجام شده است.

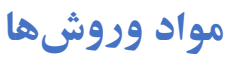

كشت بذر و تكثير و تيمار نوشاخه ها

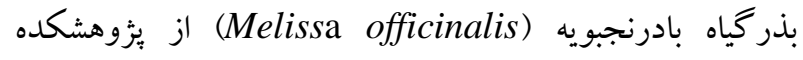

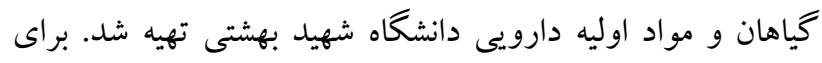

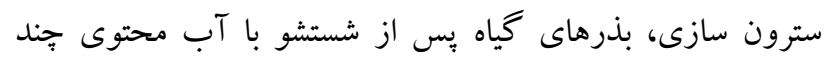

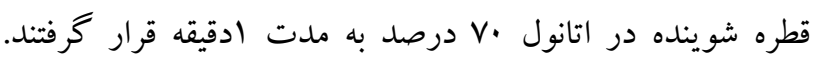

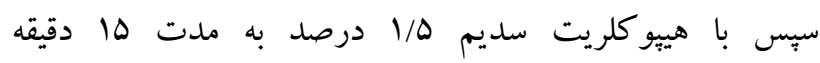

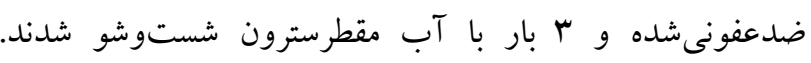

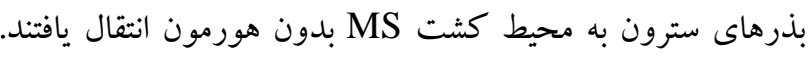

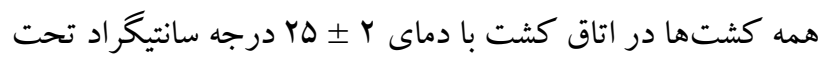

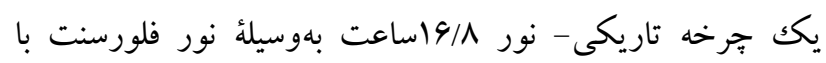
انرزى لهاه ميكرومول بر متر مربع بر ثانيه قرار گرفتند.

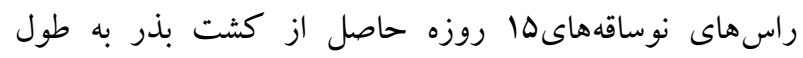
تقريبى هA cm • •، جهت تكثير به محيط كشت MS حاوى

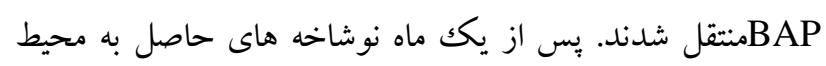

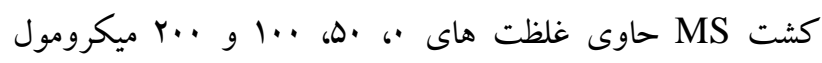

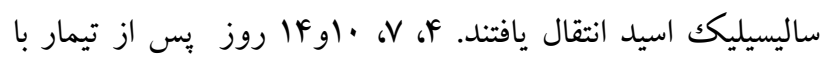

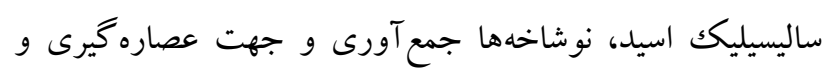
سنجش مورد استفاده قرار گرفتند.

تهية عصارة متانلى

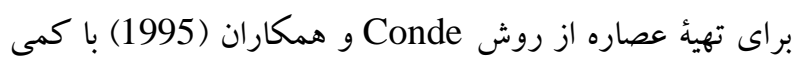

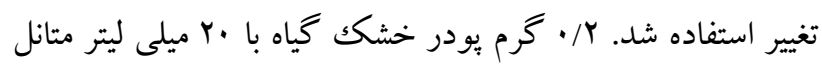

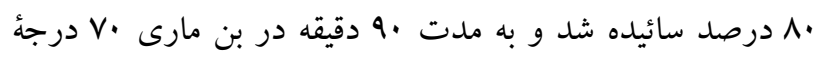

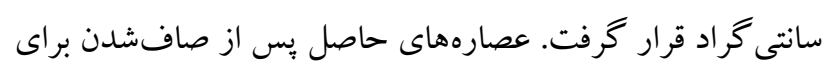
انجام سنجش ها مورد استفاده قرار كرفتند.

\section{سنجش رزمارينيك اسيد، تركيبات فنلى و فلاونوئيدى}

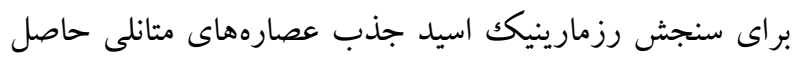

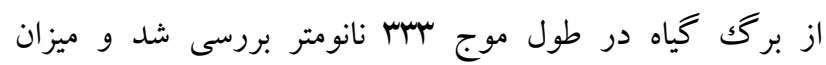


كاهشى هم در همين تيمار مشاهده شد (YV/\&

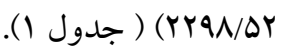
در غياب ساليسيليك اسيد مقدار رزمارينيك اسيد با افزايش زمان

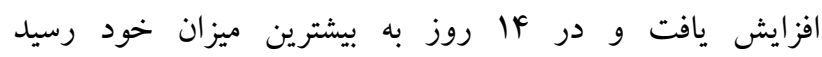
(99//V士•/V mg /g DW) شده با ساليسيليك اسيد هم مشاهده شد. مؤثرترين غلظت براى سنتز رزمارينيك اسيد غلظت ..1 ميكرومولار ساليسيليك اسيد

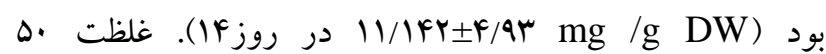
ميكرومولار ساليسيليك اسيد در روز IF اثر بيشترى بر سنتز

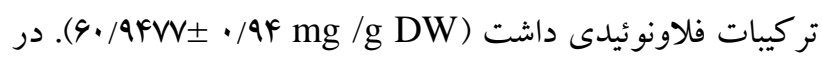
كل ساليسيليك اسيد با غلظت ..1 ميكرومولار در روز تشخيص داده شد. با افزايش غلظت ساليسيليك اسيد كاهش در بارامترهاى اندازه گيرى شده مشاهده شد ( جدول (1) ).

بحث ساليسيلك اسيد و مشتقات آن بر فعاليت هاى فيزيولوزيكك و

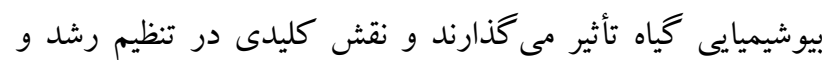

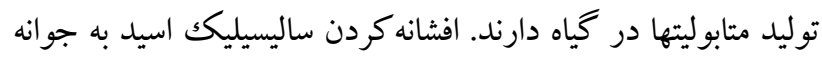
هاى كياه جو اين نتايج را تائيد مى كند) (Pancheva et al., 1996).

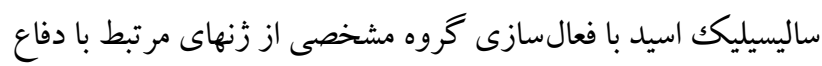

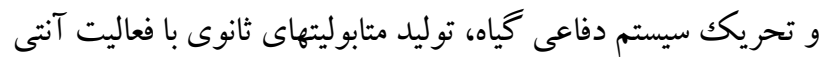
اكسيدانى را افزايش مى دهد (Lee et al., 2003). ساليسيليك اسيد با جلو گيرى از فعاليت آنزيم كاتالاز و افزايش توليد سيستم دفاعى گياه را فعال مى كند (Chen et al., 1993).

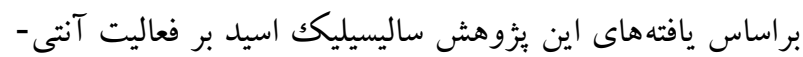

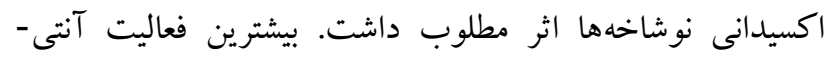

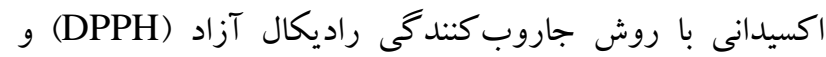
سنجش قدرات احيايى(RP) در نوشاخههاى تيمارشده با غلظت

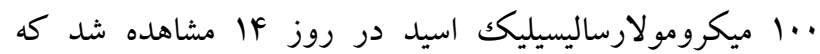
متناسب با بيشترين مقدار تركيبات فنلى و رزمارينيك اسيد بوده.

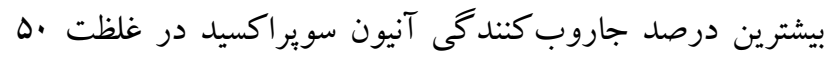

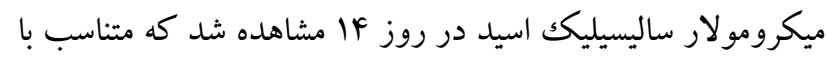

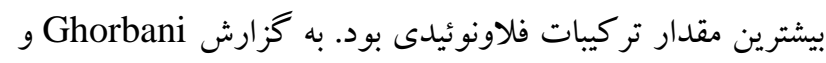

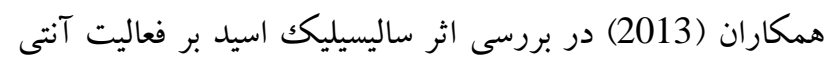

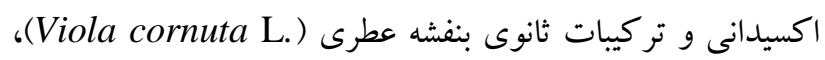

جذب در ل V. نانومتر خوانده شد. قدرت كاهشى به عنوان

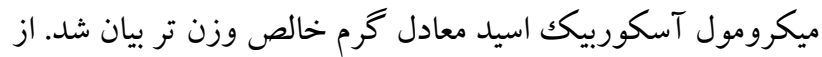
منحنى استاندارد آسكوربيك اسيد در دامنه · تا ..اميكرو مولار براى كاليبر كردن استفاده شد (Niciforovica et al., 2010). سنجش فعاليت جاروب كنندكى آنيون سوير اكسيد

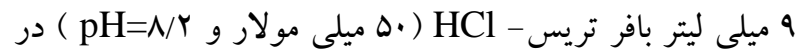

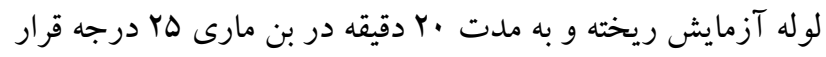

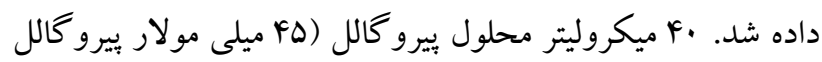
در ·ا ميلى مولار HCl ) به تركيب بالا اضافه و بعد از r دقيقه

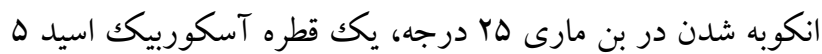
درصد به آن اضافه شد. بعد از ه دقيقه جذب آن در . . ن نانومتر خوانده و بعنوان A در نظر كرفته شد. در لوله ديخر به جاى آسكوربيكك اسيد عصارة گياهى ريخته شد و جذب آن بعد از ها هانه دقيقه در .Fq نانومتر خوانده شد و بعنوانA در نظر گرفته شد. در كه به عنوان شاهد در نظر گرفته شد به جاى عصاره آب مقطر ريخته شد. درصد جاروب كنندگى با استفاده از فرمول زير محاسبه

شد (Jiao et al., 2005): ( ) 的

تحليل آمارى آزمايشها بر يايه طرح كاملا تصادفى با ب تكرار انجام شد. در موارد

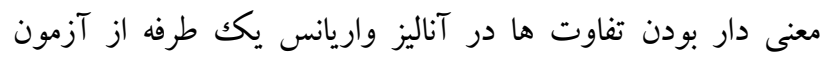

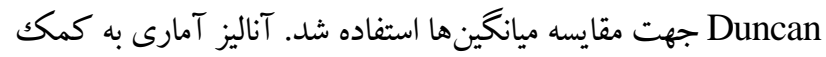

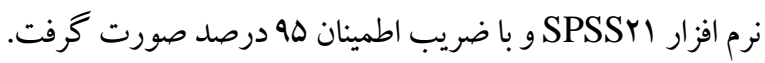

\section{نتايج}

در غياب ساليسيليك اسيد بيشترين فعاليت آنتىاكسيدانى با قدرت كاهشى در روز fi أ و بيشترين درصد فعاليت آنيون سوير اكسيد در روز جهارم مشاهده شد (

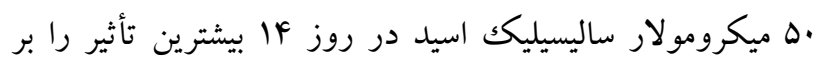

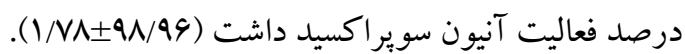
تغييرات تركيبات فنلى و فلاونوئيدى و ميزان IC50 در غير دياب ساليسيليك اسيد خيلى محسوس نبود و غلظت . .1 ميكرومولار

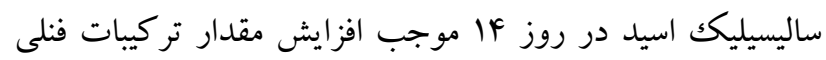

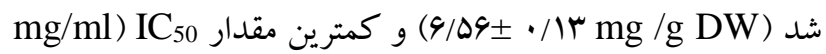
r 


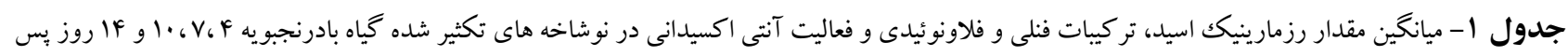

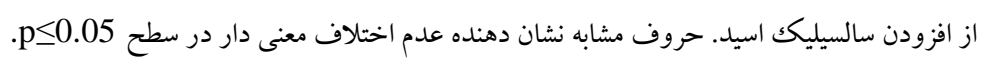

Table. 1. The mean of Rosmarinic acid, phenolics and flavonoid compounds amounts and antioxidant activity in proliferated shoots of Melissa officinalis 4, 7, 10 and 14, days after adding salicylic acid. Similar letters indicate no significant difference at the level of $\mathrm{p} \leq 0.05$.

\begin{tabular}{|c|c|c|c|c|c|c|c|}
\hline درصد جاروب كنند & قدرت كاهشى & $\begin{array}{l}\text { IC50 } \\
(\mu \mathrm{g} / \mathrm{ml})\end{array}$ & $\begin{array}{c}\text { تركيات فلاونوئيدى (mgQE/gdw) } \\
\text { (mgE) }\end{array}$ & $\begin{array}{l}\text { تركيبات فنلى } \\
\text { (mgGA/gdw) }\end{array}$ & $\begin{array}{l}\text { رزمارينيك اسيد } \\
\text { ( } \mu \mathrm{g} / \mathrm{ml} \mathrm{RA})\end{array}$ & روز & 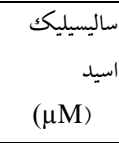 \\
\hline $91 / \wedge V \pm 1 / \cdot \wedge^{\text {ef }}$ & $\Lambda ৭ V / F r \pm r V / q V^{c d}$ & $\cdot / \cdot r \cdot \pm \cdot / \cdot \cdot r$ de & $F / q 1 \pm \cdot / F F^{\prime}$ de & $\Delta / r \varphi \pm \cdot / \cdot \Delta$ cde & $\Delta \cdot / / r r \pm 1 / 4 \Lambda^{a}$ & F & . \\
\hline$\wedge ৭ / ৭ ৭ \pm 1 / \cdot \wedge^{\mathrm{de}}$ & $V G \Psi / I Y \pm Y Y / I^{a}$ & $\cdot / \cdot r \Delta \pm \cdot / \cdot \cdot q^{\mathrm{fg}}$ & $F / N F \pm \cdot / F q^{\mathrm{de}}$ & $\Delta / 19 \pm \cdot / \cdot \Delta^{\mathrm{bcd}}$ & $F \Delta / G r Y \pm \cdot / \kappa r^{a}$ & v & . \\
\hline $99 / \mathrm{AV} \pm \cdot / 9 Y^{\mathrm{b}}$ & $v_{\Delta} \cdot / 91 \pm r q / 9 r^{\mathrm{ab}}$ & $\cdot / \cdot \mathrm{rV} \pm \cdot / \ldots \mathrm{rhi}^{\mathrm{hi}}$ & $r / \Delta F \pm \cdot / r q^{a}$ & $\Delta / \cdot 9 \pm \cdot / \cdot \Delta^{b}$ & $9 \Delta / 99 \Delta \pm \cdot / V^{F^{b}}$ & 1. & . \\
\hline$\Delta r / 4 r \pm \cdot \Delta r^{c d}$ & $I r \cdot \Lambda / V \Lambda \pm r V / Q V^{g}$ & $\cdot / \cdot r \pm \cdot / \ldots r^{f}$ & $F / N F \pm \cdot / / V^{\mathrm{de}}$ & $\Delta / Y \backslash \pm \cdot / 1$. bcd & $1 \cdot V / \Lambda \Delta r \pm I r / r \Delta \Delta^{d}$ & if & . \\
\hline$\Lambda M / / Y \pm 1 / \cdot \Lambda^{\mathrm{de}}$ & $\Lambda q V / F r \pm r \Lambda / / r^{c d}$ & $\cdot / \cdot 19 \pm \cdot / \cdots \wedge^{c d}$ & $r / \wedge ৭ \pm \cdot / r r^{b c d}$ & $\Delta / F \mid \pm \cdot / \cdot \wedge \mathrm{de}$ & $V N / 4 \cdots \pm 1 / r \Delta \Delta^{b c}$ & F & $\Delta$. \\
\hline$V \cdot / \cdot a \pm r / V r^{b}$ & $1 . k r / q \Delta \pm r \mid / V r^{e f}$ & $\cdot / \cdot 1 v \pm \cdot / \cdots \mu^{c}$ & $r / r 1 \pm \cdot / 19^{\mathrm{ab}}$ & $\Delta / \Delta 9 \pm \cdot / \cdot \wedge \mathrm{e}$ & $\Lambda \mathrm{N} / \Delta \mathrm{\Delta r} \pm 1 / \mathrm{V \Lambda}{ }^{\mathrm{c}}$ & $v$ & $\Delta$. \\
\hline$\Lambda ৭ / 9 \wedge \pm \mathrm{r} / \Delta \mathrm{V}^{\mathrm{de}}$ & $\Delta V Q / / 1 \pm \Delta N / A V^{\mathrm{bc}}$ & $\cdot / \cdot r f \pm \cdot / \cdots r^{f}$ & $\Delta / V G \pm \cdot / / V^{a b}$ & $\Delta / Y \backslash \pm \cdot / \cdot \Delta^{\mathrm{bcd}}$ & $V r / 9 \cdot \ldots \pm r / 9 q^{b c}$ & 1. & $\Delta$. \\
\hline $9 / / 99 \pm 1 / V \Lambda^{g}$ & $1 V \cdot q / r q \pm q \cdot / / r^{i}$ & $\cdot / r \Delta \pm \cdot / \cdots r^{\mathrm{fg}}$ & $9 / \mathrm{VV} \pm \cdot / 9 F^{f}$ & $\Delta / 19 \pm \cdot / \cdot \Delta^{\mathrm{bcd}}$ & $1.9 / \Delta \Delta 9 \pm Y / 9 \Delta^{d}$ & if & $\Delta$. \\
\hline$V Q / r V \pm 1 / \cdot r^{c}$ & $\mid q F \cdot / N V \pm \& q / q q^{h}$ & $\cdot / \cdot 1 \mathrm{~V} \pm \cdot / \cdot \cdot 1 f^{\mathrm{c}}$ & $\Delta / V G \pm \cdot / \Gamma F^{\text {ef }}$ & $\Delta / \Delta 9 \pm \cdot / \cdot \wedge^{\mathrm{e}}$ & $9 \Delta / 99 \cdot \pm r / 99^{b}$ & F & 1.. \\
\hline$\Lambda 9 / \Delta \cdot \pm 1 / \mathrm{V} \Lambda^{\text {cde }}$ & $9 \uparrow 9 / \mathrm{YV} \pm 9 / 1 . \mathrm{cde}$ & $\cdot / \cdot r \wedge \pm \cdot / \cdots r^{\mathrm{i}}$ & $F / \Delta V \pm \cdot / q^{d}$ & $\Delta / \cdot 9 \pm \cdot / \cdot \Delta^{b}$ & $\Delta r / \Delta \cdot 9 \pm \cdot / 9 \mu^{a}$ & v & 1.. \\
\hline $9 \mathrm{Q} / \mathrm{r} \pm \cdot / \wedge 9^{\mathrm{ef}}$ & $1 . \Delta 9 / 19 \pm \& q / 9 q^{e f}$ & $\cdot / r \mid \pm \cdot / \cdots \Lambda^{\mathrm{e}}$ & $\Delta / \cdot \wedge \pm \cdot / Y q^{\mathrm{de}}$ & $\Delta / \mu I \pm \cdot /$. bcde & $99 / \cdot v 9 \pm r / 11^{b}$ & 1. & $1 .$. \\
\hline$\Lambda \cdot / 4 \cdot \pm 1 / v \Lambda^{c}$ & $T Y F G / G T \pm \Delta F / r \Delta^{j}$ & $\cdot / \cdot \mid r \pm \cdot / \cdots r^{\mathrm{a}}$ & $\Gamma / \Upsilon^{\prime} \wedge \pm \cdot / 19^{\mathrm{abc}}$ & $9 / 09 \pm \cdot / 1 r^{g}$ & $\mid F r / 11 \cdot \pm F / q r^{e}$ & if & $1 .$. \\
\hline$\Lambda 9 / 9 \wedge \pm 1 / N \Lambda^{\mathrm{de}}$ & $\mid r q \Lambda / \cdot r \pm \Delta F / r q^{h}$ & $\cdot / \cdot 10 \pm \cdot / \cdots r^{b}$ & $4 / .9 \pm \cdot / q^{\text {bcd }}$ & $\Delta / \wedge 9 \pm \cdot^{f}$ & $\mathrm{~V} / / 9.9 \pm 1 / 9 \mathrm{Ac}^{\mathrm{bc}}$ & $F$ & $r \cdot \cdot$ \\
\hline 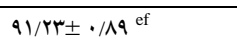 & $1.1 \% / F r \pm Y F / F Y$ def & $\cdot / \cdot r \pm . / \cdots r^{f}$ & $r / \Lambda q \pm \cdot / / V^{\text {bed }}$ & $\Delta / r \mid \pm \cdot / \cdot \Delta^{\text {bcd }}$ & $9 \mathrm{~V} / 909 \pm \cdot / T \mathrm{~A}^{\mathrm{b}}$ & v & $r \cdot \cdot$ \\
\hline$q \vee / 4 \backslash \pm 9 / Y F^{f g}$ & $\| 1 \cdot \Delta / \cdot \cdot \pm|r / r|^{\mathrm{fg}}$ & $\cdot / r 9 \pm \cdot / \ldots r^{\text {gh }}$ & $F / F \cdot \pm \cdot / / V^{c d}$ & $\Delta / 11 \pm \cdot / 1 \Delta^{\mathrm{bc}}$ & $\Lambda r / \Lambda g r \pm r / r \cdot{ }^{c}$ & 1. & $r \cdot$. \\
\hline$\Delta 9 / 99 \pm r / V r^{a}$ & $1 \cdots|/ r| \pm r V / \mid r^{c d e f}$ & $\cdot / \cdot r \cdot \pm \cdot / \cdots q^{j}$ & $r / \Delta F \pm$, ${ }^{a}$ & $F / N G \pm \cdot / / r^{a}$ & $1 \cdot r / \mu r r \pm 1 / \Delta r^{d}$ & if & $r \cdot \cdot$ \\
\hline
\end{tabular}

تركيبات فلاونوئيدى در جاروب كردن آنيون سويراكسيد نقش دارند و در نتايج ما بيشترين مقدار فلاونوئيد متناسب با بيشترين درصد جاروب كردن آنيون سوير اكسيد بود. با افزايش غلظت ساليسيليك اسيد مقدار فلاونوئيدها كاهش يافت. از آن جايى كه مقدار كل تركيبات فنلى با افزايش غلظت ساليسيليك اسيد تغيير زيادى نشان نداد، مىتوان اين فرايند را به سنتز ساير تركيبات آنتى اكسيدانى نسبت داد. در گياه آناغاليس (Anagallis tenella L.)

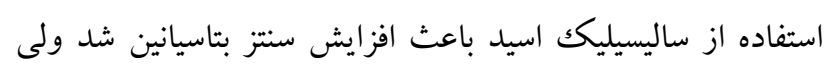

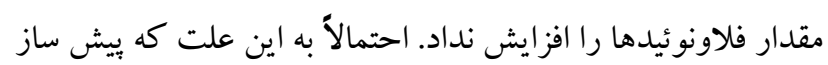

افزايش مقدار ساليسيليك اسيد اثر معنىدارى بر افزايش فعاليت آنتى اكسيدانى با روش جاروب كنندگى راديكال آزاد (DPPH)

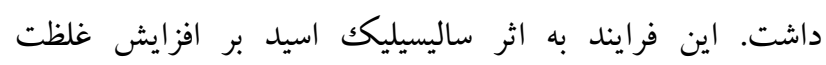
تر كيبات فنلى و فعاليت آنزيم فنيل آلانين آمونيالياز نسبت داده شد. اين نتايج در راستاى نتايج اين يثوهش است.

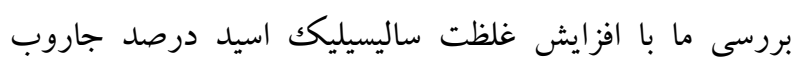
كنندكى آنيون سوير اكسيد كاهش يافت و غلظت • له ميكرومولار ساليسيليك اسيد اثر بيشترى بر درصد جاروب كنندكى آنيون سوير اكسيد داشت. به گزارش Robak و Glyglewski (1988) 
(2014) در گياه نعنا (Mentha piperita L) مطابقت داشت. به كزارش اين محققين محتواى تركيبات فنلى در حضور ساليسيليك اسيد افزايش يافت اما مقدار فلاونوئيدها كاهش يافت و Nicholson Shabrangi \& BeigiJazi, 2014) فاليت آن نم فنرا Hammerschmidt فعاليت آنزيم فنيل آلانين آمونيالياز مى شود كه يك آنزيم كليدى در مسير سنتزتر كيبات فنلى است ولى فعاليت جالكون سنتاز (CS)

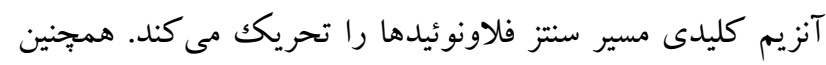

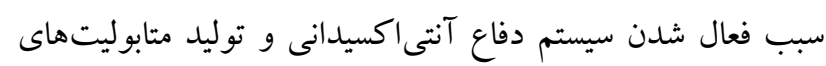

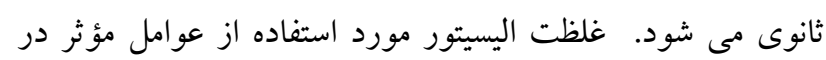
مقدار سنتز متابوليتهاى ثانوى است. از اين رو علت تفاود عات درد نتايج محققين مختلف را مى توان به غلظت ساليسيليك اسيد مورد

استفاده نسبت داد (Namdeo, 2007).

در مجموع ساليسيليك اسيد به ويزه در غلظت ... . ميكرومولار بر فعاليت آنتى اكسيدانى و تر كيبات آنتى اكسيدانى كياه بادرنجبويه

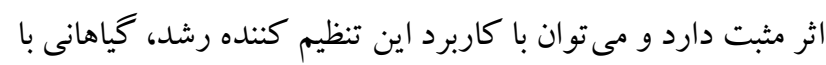

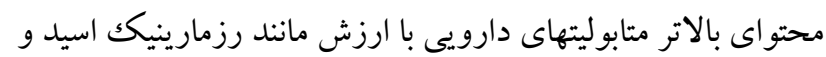

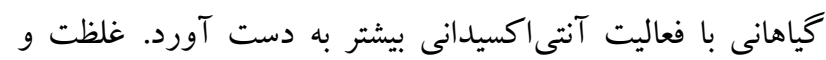

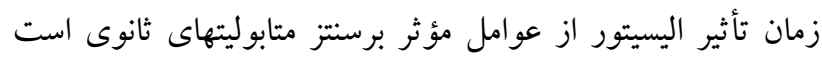

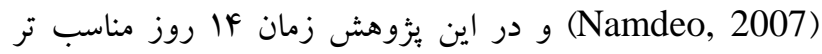

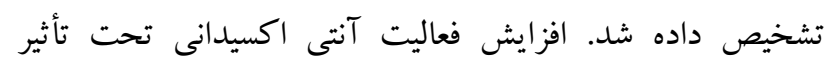
ساليسيليك اسيد به توانايى اين ماده در توليد

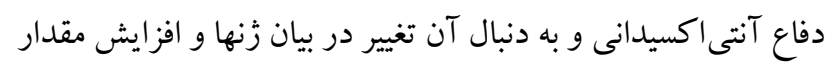

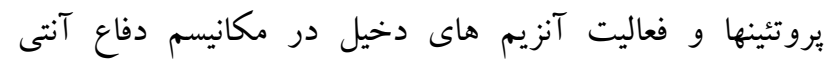

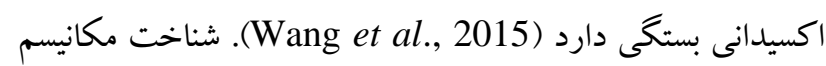
دقيق تر اثر ساليسيليك اسيد بر فعاليت آنتى اكسيدانى به بزروهش دارد إنى

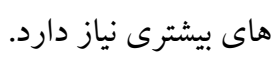

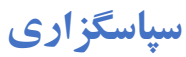

نويسند كان از دانشكاه الزهرا به دليل حمايت مالى از يزوهش

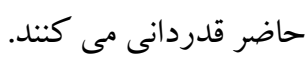

\section{REFERENCES}

Brandão, I.R., Kleinowski, A.M., Einhardt, A.M., Lima, M.C., Amarante, L.D., Peters, J.A. and Braga, E.J.B. 2014. Salicylic acid on antioxidant activity and betacyanin production from leaves of Alternanthera tenella. - Ciênc. Rural. 44: 1893-1898.
مشترك دو تركيب، تيروزين است كه ترجيحا به بتاسيانين تبديل مى شود (Brandão et al., 2014). در اين ئزوهش با افزايش غلظت ساليسيليك اسيد تا ..1.

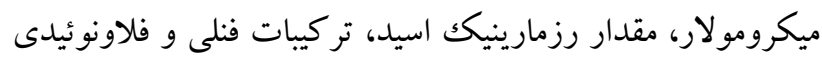

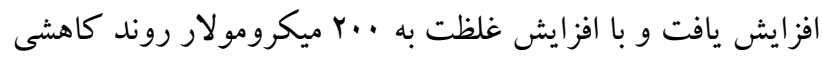

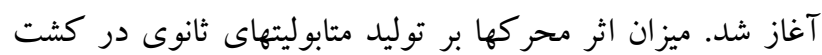

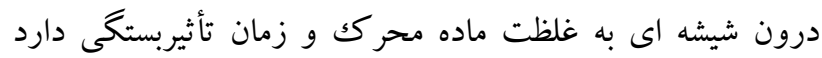
(Wen et al., 2008)

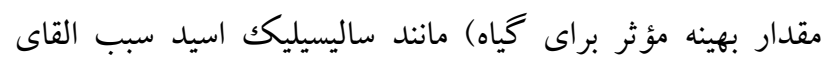

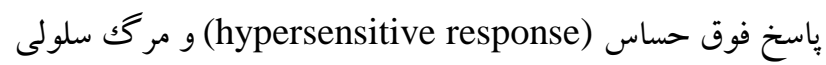

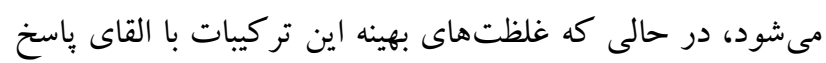

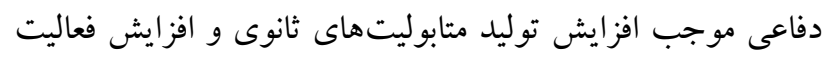

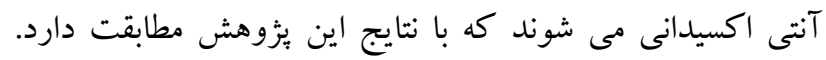

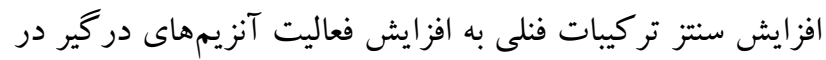

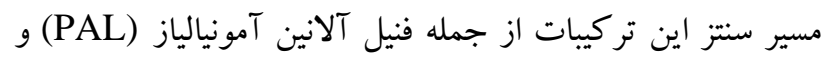

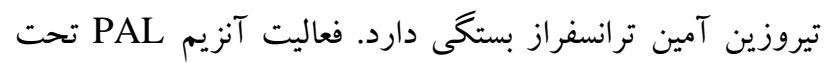

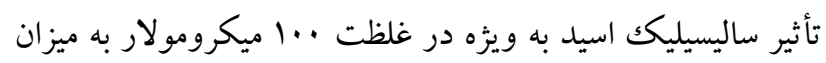

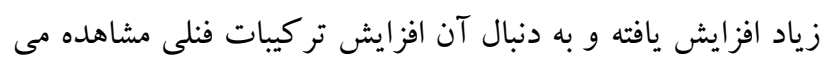

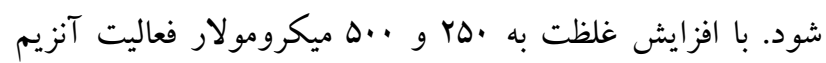
كاهش يافت ( Dogbo et al., 2012 (T).

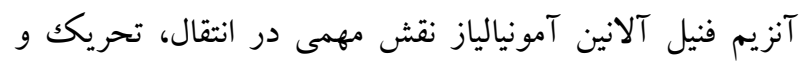
سنتز تركيبات مسير فنيليرويانوئيد و تنظيم بيان زنهاى دفاعى به الهيه

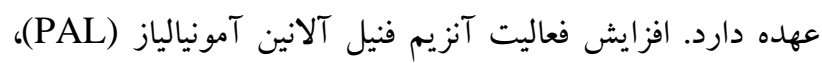

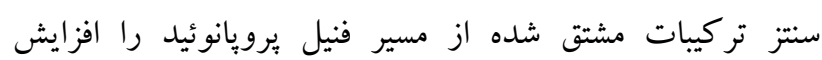

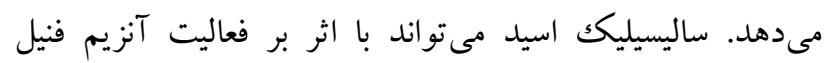

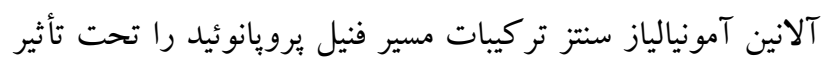
قرار دهد (Nurgroho et al., 2002). در كشت ريشه موئى گياه ريحان (Ocimum basilicum L.) ساليسيليك اسيد با فعال كردن سيستم دفاعى گياه و به دنبال آن القاى مسير فنيل برويانوئيد باعث افزايش توليد رزمارينيك اسيد شد (Matkowski, 2008). در اين إزوهش بيشترين مقدار تركيبات فلاونوئيدى در نوشاخه

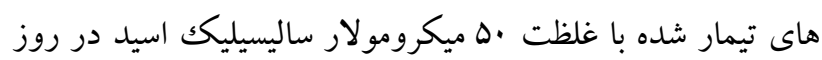

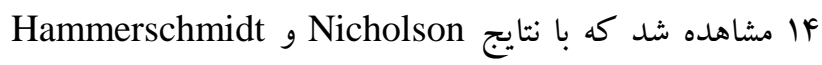
(1992) مطابقت داشت. كاهش در مقدار تر كيبات فلاونوئيدى با با بأج

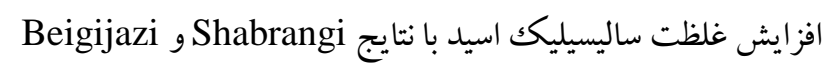


Buitelaar, R.M., Casário, M.T. and Tramper, J. 1992. Elicitation of thiophene production by hairy roots of Tagetespatula. - Enzy. Microbiol. Technol. 14: 2-7.

Chen, Z., Silva, S. and Klessig, D.F. 1993. Active oxygen species in the induction of plant systemic acquired resistance by salicylic acid. - Science 262: 18831886.

Conde, E., Cadahia, E. and Garcia-Vallejo, M.C. 1995. HPLC analysis of flavonoids and phenolic acids and aldehydes in Eucalyptus spp. - Chromatographia 41:657-660.

Dogbo, D.O., Gogbeu, S.J., N'zue., B., Yao, K.A., Zohouri, G.P., Mamyrbekova-Bekro, J.A. and Bekro Y.A. 2012. Comparative activities of phenylalanine ammonia-lyase and tyrosine ammonia-lyase and phenolic compounds accumulated in Cassava elicited cell. - Afri. Crop. Sci. J. 20: 85-94.

Ebrahimi, M., Kiarostami, Kh.and Nazem Bokaee, $Z$. 2015. The effect of different concentrations of kinetin on Melissa officinalis micropropagation and rosmarinic acid content in tissue culture. 18th National and 6th International Congress of Biology, Tehran. pp: 26-29.

Fletcher, R.S., Slimmon, T., McAuley. C.Y and Kott, L. 2005. Heat stress reduces the accumulation of rosmarinic acid and the total antioxidant capacity in spearmint ( Mentha spicata L.). - Sci. Food . Agri. 85: 2429-2436.

Gorbani, N., Moradi, H., Akbarpour, A. and Ghasemnezhad, A. 2013. The phytochemical changes of violet flowers (Viola cornuta) response to exogenous salicylic acid hormone. - JCHR. 3:1-8.

Hayat, S., Hasan, S.A., Fariduddin, Q. and Ahmad, A. 2008. Growth of tomato (Lycopersicon esculentum) in response to salicylic acid under water stress. - Int. J. Plant. Sci. 3: 297-304.

Jiao. Z, Liu, J. and Wang, S. 2005. Antioxidant activity of total pigment extract from Blackberries - Food. Technol. Biotech. 43 : 97-102.

Kiarostami, Kh., abdolmaleki, N. and Heydari, M. 2013. Effect of salicylic acid on salinity stress reduction in canola. - Plant Biol. 4: 69- 82.

Kulisic-Bilusic, T., Katalinic,V., Dragovic-Uzelac,V., Ljubenkov, I., Krisco, A., Dejannovic, B. and Jukic, M. 2008. Antioxidant and acetylcholinesterase inhibiting activity of several aqueous tea infusions in vitro - Food. Technol. Biotech. 46: 368-375.

Khaki, A., Imani, S.A.M. and Golzar, S. 2012. Effects of rosmarinic acid on male sex hormones (testosteroneFSH-LH) and testis tissue apoptosis after exposure to electromagnetic field (EMF) in rats. - Afr. J. Pharm. Pharmaco. 6: 248-252.

Lee, S.E., Hwang, H.J., Ha, J.S., Jeong, H.S. and Kim, J.H. 2003. Screening of medicinal plant extracts for antioxidant activity. - Life. Sci. 73: 167-179.

Lopez-Arnaldos, T., Lopez-Serrano, M., Ros., Barcelo, A., Calderon, A.A. and Zapata, J.M. 1995. Spectrophotometric determination of rosmarinic acid in plant cell cultures by complexation with $\mathrm{Fe}^{2+}$ ions. Fresen. J. Anal. Chem.- 351: 311-314.
López Arnaldos, T., Muñoz, R., Ferrer, M.A and Calderón, A.A. 2001 .Change in phenol content during straberry callus. - Plant. Physiol. 113:315-322.

Matkowski, A. 2008. Plant in vitro culture for the production of antioxidants. - Biotechnol. Adv. 26: 548-560.

Meftahizade, H., Moradkhani, H., Naseri, B., Lotfi, M. and Naseri, A. 2010. Improved in vitro culture and micropropagation of different Melissa officinalis L. genotypes. - J. Med. Plants. Res. 4: 240-246.

Meftahizade, M., Lotfi, M. and Moradkhani, H. 2012. Optimization of micropropagation and establishment of cell suspension culture in Melissa officinalis L. Afr. J. Biotechnol. 9: 4314-4321.

Mohebalipour, N., Aharizad, S., Mohammadi, S., Motallebiazar, A. and Arefi, H.M. 2012 . Effect of .plant growth regulators BAP and IAA on micropropagation of Iranian lemon balm (Melissa officinalis L.) landraces. - J. Food. Agric. Environ. 10: 280-286.

Mohamadi, S., Kiarostami, Kh.and Nazem Bokaii, Z. 2014. The Study of antioxidant property of metanolic extracts of Melissa officinalis L. and Salvia officinalis L. on stability of soybean oil. - J. Agroaliment. Proc. Technol. 20: 293-297.

Molyneux, P. 2004. The use of the stable free radical diphenylpicryl-hydrazyl (DPPH) for estimating antioxidant activity. - J. Sci. Technol. 26: 211-219.

Namdeo, A.G. 2007. Plant cell elicitation for production of secondary metabolites-A review. - Pharm. Rev. 1: 69-79.

Niciforovic, N., Mihailovic, V., Maskovic, P., Solujic,S., Stojkovic, A. and PavlovicMuratspahic, D. 2010. Antioxidant activity of selected plant species; potential new sources of natural antioxidants. - Food Chem. Toxicol. 48: 3125-3130.

Nicholson, R.L. and Hammerschmidt, R. 1992. Phenolic compounds and their role in disease resistance. Annu. Rev. Phytopathol. 30: 369-389.

Nurgroho, L.H., Verberne, M.C and Verpoorte, R. 2002 .Activities of enzymes involved in the phenylpropanoid pathway in constitutively salicylic acid-producing tobacco plants. - Plant Physiol. Bioch. 40: 755-760.

Ozturk, M.E., Duru, M., Burco, I., Harmandar, M. and Topcu, G. 2010. A new rapid spectrophotometric method to determine the rosmarinic acid level in plant extracts. - Food. Chem. 123. 1352-1356.

Ondrejovic. M., Kraic. F., Benkovicova, H. and Silhar, S. 2012. Optimization of antioxidant extraction from Lemon Balm (Melissa officinalis). - Czech. J. Food. Sci. 30: 385-393.

Pancheva, T.V., Popova, L.P. and Uzunova, A.N. 1996. Effect of salicylic acid on growth and photosynthesis in barley plants. - J. Plant. Physiol. 149: 57-63.

Peeva, G., Penchevb, P., Pesheva, D. and Angelovb, G. 2011. Solvent extraction of rosmarinic acid from lemon balm and concentration of extracts by nanofiltration: Effect of plant pre-treatment by supercritical carbon dioxide. - Chem. Eng. Res. Des. 89: 2236-2243. 
Raskin, I. 1992. Role of salicylic acid in plants. - Annu. Rev. Plant Biol. 43: 439-463.

Raghavendra, H., Vijayananda, B., Madhumathi,G. and Hiremath, A. 2010.In vitro antioxidant activity of Vitexnegundo L. Leaf extracts. - Chiang Mai. J. Sci. 37: 489-497.

Robak, J. and Gryglewski, R.J. 1988. Flavonoids are scavengers of superoxide anions. - Biochem. Pharmacol. 37: 837-841.

Rowshan, V., Khosh Khoi, M. and Javidnia, K. 2010. Effects of salicylic acid on quality and quantity of essential oil components in Salvia macrosiphon. - J. Biol. Environ. Sci. 4: 77-82.

Sakhanokho, H.F. and Kelley, R.Y. 2009. Influence of salicylic acid on in vitro propagation and salt tolerance in Hibiscus acetosella and Hibiscus moscheutos (cv 'Luna Red'). - Afr. J. Biotechnol. 8: 1474-1481.

Shabrangi, A. and BeigiJazi, E.A. 2014. Effect of salicylic acid on the amount of essential oil, phenolic compo-unds, flavonoids and antioxidant activity of Mentha piperita L. - Int. J. Agric. Crop. Sci. 7-8: 499-502.

Shahadat Hossan, M.D., Shiblur Rahman, A.B.M., Anwarul Bashar, A.B.M. and Rahmatollah, M. 2014. Rosmarinic acid :A review of its anticancer. - W. J. Pharm. Pharmace. Sci. 3: 57-70

Weitzel, C. and Petersen, M. 2011. Cloning and characterisation of rosmarinic acid synthase from Melissa officinalis L. - Phytochem. 72 : 572-578.
Wang, Z., Ma, L., Zhang, X., Xu, L., Cao, J. and Jiang, W. 2015. The effect of exogenous salicylic acid on antioxidant activity, bioactive compounds and antioxidant system in apricot fruit. - Scientia. Hort. 181: 113-120.

Wen, P.F., Chen, J.Y., Wan, S.B., Kong, W.F., Zhang, P., Wang, W., Zhan, J.C., Pan, Q.H. and Huang, W.D. 2008. Salicylic acid activates phenylalanine ammonia lyase in grape berry in response to high temperature stress. - Plant .G. Regu 55: 1-10.

Yosofi, M., Hojjati , M.R., Moshtaghi, E., Rahimiyan, R., Dawodiyan Dehkordi, A. and Rafieian, M. 2011. The effect of hydro-alcoholic extract of Melissa officinalis on learning and spatial memory in Balb/c mice. - J. Shahrekord. Uni. Med. Sci. 13: 51-59.

How to cite this article:

Ebrahimi, M., Kiarostami, Kh. and Nazem Bokaee, Z. 2019. Effect of salicylic acid on antioxidant properties of in vitro proliferated shoots of Melissa officinalis L. - Nova Biol. Reperta 5: 420-427.

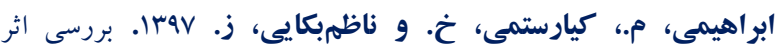

ساليسيليك اسيد بر فعاليت آنتىاكسيدانى نوشاخههاى تكثيرشده

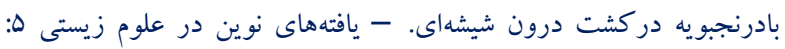
FY. FYY 